\title{
The role of consciousness in cognitive control and decision making
}

\author{
Simon van Gaal ${ }^{1,2}$, Floris P. de Lange ${ }^{3}$ and Michael X Cohen ${ }^{4}$ \\ Institut National de la Santé et de la Recherche Médicale, Cognitive Neuroimaging Unit, Gif-sur-Yvette, France \\ ${ }^{2}$ Commissariat à l'Energie Atomique, Neurospin Center, Gif-sur-Yvette, France \\ ${ }^{3}$ Donders Institute for Brain, Cognition and Behavior, Radboud University Nijmegen, Nijmegen, Netherlands \\ ${ }^{4}$ Department of Psychology, University of Amsterdam, Amsterdam, Netherlands
}

\author{
Edited by: \\ Tilmann A. Klein, Max Planck \\ Institute for Human Cognitive and \\ Brain Sciences, Germany \\ Reviewed by: \\ Tobias Egner, Duke University, USA \\ Catherine A. Orr, University of \\ Melbourne, Australia \\ *Correspondence: \\ Simon van Gaal, Institut National de \\ la Santé et de la Recherche \\ Médicale U992/NeuroSpin, \\ Cognitive Neuroimaging Unit, \\ Gif-sur-Yvette, CEA - Saclay, France. \\ e-mail: simonvangaal@gmail.com
}

Here we review studies on the complexity and strength of unconscious information processing. We focus on empirical evidence that relates awareness of information to cognitive control processes (e.g., response inhibition, conflict resolution, and task-switching), the life-time of information maintenance (e.g., working memory) and the possibility to integrate multiple pieces of information across space and time. Overall, the results that we review paint a picture of local and specific effects of unconscious information on various (high-level) brain regions, including areas in the prefrontal cortex. Although this neural activation does not elicit any conscious experience, it is functional and capable of influencing many perceptual, cognitive (control) and decision-related processes, sometimes even for relatively long periods of time. However, recent evidence also points out interesting dissociations between conscious and unconscious information processing when it comes to the duration, flexibility and the strategic use of that information for complex operations and decision-making. Based on the available evidence, we conclude that the role of task-relevance of subliminal information and meta-cognitive factors in unconscious cognition need more attention in future work.

\section{INTRODUCTION}

Although at first controversial, it is now generally accepted that several perceptual, emotional and cognitive processes can unfold in the absence of awareness. Laboratory examples of this are the processing of subliminal (unconscious) words and numbers (Marcel, 1983; Merikle and Reingold, 1990; Greenwald et al., 1996; Dehaene et al., 1998; Kiefer and Spitzer, 2000), pictures of faces/houses (Sterzer et al., 2008; Kouider et al., 2009), tools (Fang and He, 2005), and emotional material such as angry faces or eye-gaze directions (Whalen et al., 1998, 2004). Going beyond visual perception, subliminal information processing has been demonstrated for auditory (Sadaghiani et al., 2009), somatosensory (Eimer et al., 2002) and olfactory (Li et al., 2007) information. In recent years the number of processes that operate or are influenced unconsciously has increased steadily, and now include reward- and motivation-related processes (Custers and Aarts, 2005; Pessiglione et al., 2007; Capa et al., 2011) as well as decision-making (Bargh and Morsella, 2008; Pessiglione et al., 2008; Custers and Aarts, 2010). One might wonder whether there are any processes that can exclusively be performed on conscious information. In this paper we review studies that explored the boundary conditions of unconscious information processing and specifically highlight those studies that were aimed at testing the role of consciousness in cognitive control, long-term information maintenance and strategic decision-making. Here, we mainly focus on cognitive aspects of unconscious information processing, although neural data is also discussed (see van Gaal and
Lamme, in press for a review of the literature in the field from a more neural perspective).

\section{CONSCIOUSNESS AND COGNITIVE CONTROL}

Some authors have argued that there might be some (cognitive) processes truly bound to consciousness, although this is strongly debated (for reviews see Umilta, 1988; Dehaene and Naccache, 2001; Jack and Shallice, 2001; Mayr, 2004; Hommel, 2007; Kunde et al., 2012). One of the major candidates for this is cognitive control, a general term for cognitive functions that allow us to rapidly and flexibly adapt our behavior when necessary. Cognitive control functions include error detection and correction mechanisms, conflict resolution, response inhibition, and task-switching. These functions are all strongly associated with the prefrontal cortex, which many consider pivotal for generating awareness (for reviews see Rees, 2007; Dehaene and Changeux, 2011; Lau and Rosenthal, 2011).

Interestingly, some cognitive control processes can be activated by unconscious stimuli. To our knowledge, the first to show that some control processes can be initiated fully automatically and unconsciously were Eimer and Schlaghecken (Eimer and Schlaghecken, 1998; Eimer, 1999). In an impressive set of studies, they showed that unconscious (masked) arrow primes initially facilitated responses, but can also inhibit responses in certain circumstances. In their tasks, subjects generally have to respond to a target-arrow (e.g., $\gg$ ) that can be preceded by a congruent $(\gg)$ or incongruent $(\ll)$ masked prime-arrow. When the interval 
between the prime and target is short (e.g., $50 \mathrm{~ms}$ ), subjects respond faster and make fewer errors to congruent than to incongruent trials, as might be expected. However, crucially, when the delay between prime and target was increased (>100 ms), there was no response facilitation but rather automatic inhibition of these responses. This led to the counterintuitive observation that response times (RTs) were faster and error rates lower to incongruent trials compared to congruent trials (note that part of the effect might be explained by lower-level stimulus characteristics, see Lleras and Enns, 2004; Jaskowski and PrzekorackaKrawczyk, 2005; Schlaghecken and Eimer, 2006). More recently, automatic inhibition paradigms have been combined with brainimaging tools and the results suggest that automatic inhibition relies on activity in the caudate and thalamus (Aron et al.,
2003) as well as the supplementary motor areas (Sumner et al., 2007).

Recent studies have demonstrated the possibility to initiate more "voluntary" forms of response inhibition unconsciously, as studied by using the Go/No-Go task and the stop-signal paradigm (Hughes et al., 2009; van Gaal and Lamme, in press). In these tasks, subjects are required to inhibit an already initiated (stop task) or planned response (Go/No-Go task). To illustrate, in one of these experiments, subjects were instructed to respond as fast as possible to the direction of an arrow (the go stimulus), but to withhold this response when the word "STOP" (the "stop stimulus") was presented briefly and quickly after the go-arrow (Figure 1A). However, when another word (e.g., "BLUF," the "goon stimulus") was presented, subjects had to continue responding

\section{A Unmasked go-on/stop trial Masked go-on/stop trial}

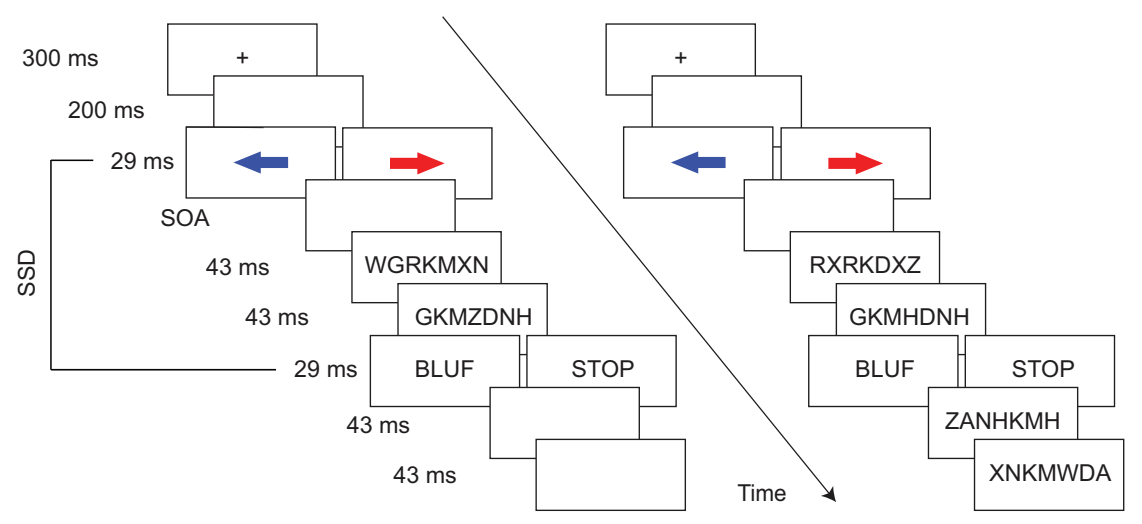

B
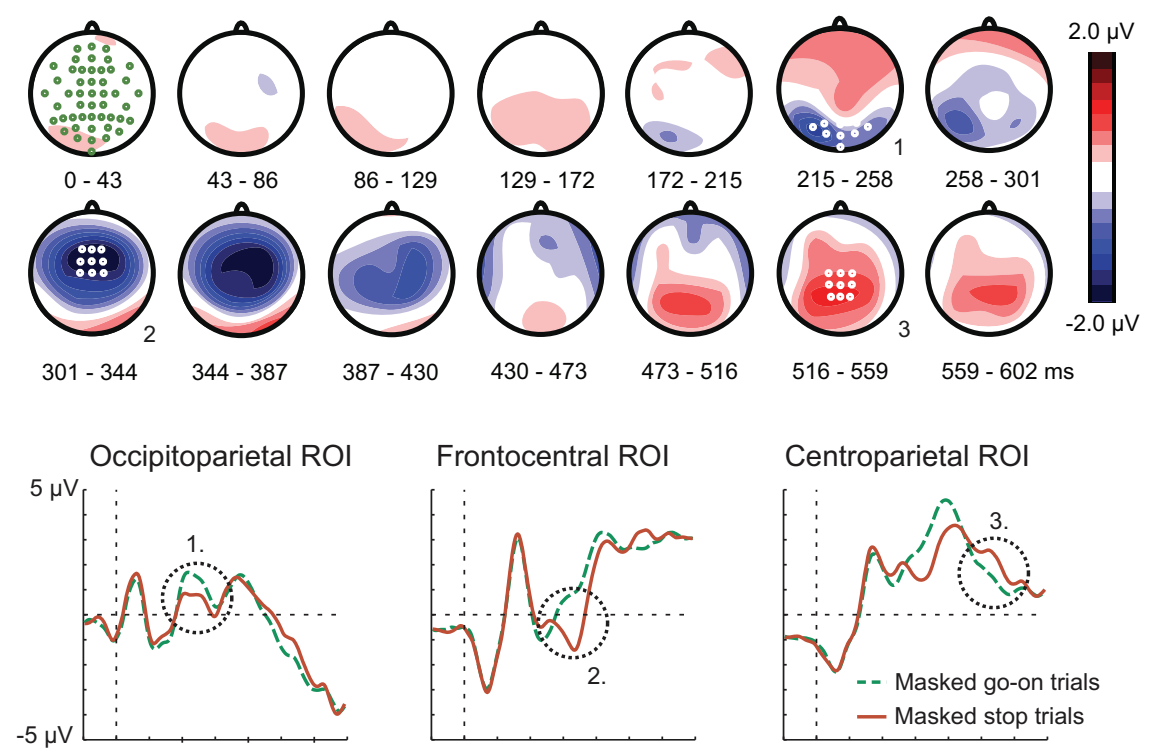

Centroparietal ROI

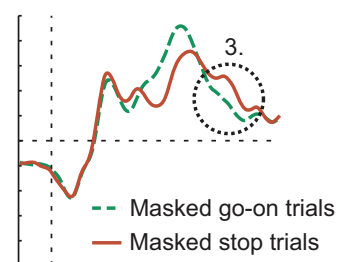

FIGURE 1 | (A) Task-set-up. (B) Electrophysiological processing across time of a masked stop-signal (the word "STOP") compared to a control "go-on" condition (e.g., the word "BLUF"). Three neural events can be distinguished: (1) an early event at occipital electrodes, (2) a middle event at fronto-central electrodes (The N2 ERP component), and (3) a late event at centro-parietal electrodes (The P3 ERP component). Adapted with permission from van Gaal et al. (2011). 
to the direction of the go-arrow. Crucially, the visibility of the stop/go-on stimulus was manipulated by presenting it in between random letter masks. Therefore, on some trials these stimuli were clearly visible, whereas on other trials they were not. Behaviorally, subjects slowed down their responses to unconscious stop-signals (compared to unconscious go-on signals), as if the STOP signal was briefly processed but not enough to cause a full response inhibition. When electrophysiological responses to unconscious stop- and go-on signals were compared, a cascade of neural events could be observed, starting early at occipital electrodes, swiftly progressing to fronto-central (the N2 ERP component) and centro-parietal electrode sites (the P3 ERP component), later in time (Figure 1B). Interestingly, in the conscious condition the magnitude of the N2 ERP component was correlated with the efficiency of inhibitory control across subjects (the stop-signal reaction time) and with the magnitude of slowdown to unconscious stop-signals. Thus, the N2 ERP component likely reflects the initiation of inhibitory control, irrespective of the conscious awareness of the control-initiating stop-signal. The frontal origin of this effect has been confirmed by source reconstruction of the EEG signals (van Gaal et al., 2008) as well as by fMRI (van Gaal et al., 2010b), in similar tasks. In fMRI, RT slowing to unconscious No-Go signals was associated with focal activations in the pre-SMA and inferior frontal cortices, bordering anterior insula (van Gaal et al., 2010b), whereas response inhibition to visible No-Go signals was related to large scale activation in a typically observed fronto-parietal "inhibition network" (Aron, 2007; Simmonds et al., 2008). The strength of activation in the unconscious inhibition network was correlated with the extent of slowdown to unconscious No-Go signals across subjects, suggesting that this activation is functional in a sense that it is related to behavioral effects of cognitive control.

Recent results suggest that several cognitive control functions other than response inhibition can be triggered by unconscious or unnoticed stimuli (for a recent review see van Gaal and Lamme, in press), including task-set preparation (Mattler, 2003; Lau and Passingham, 2007; van Opstal et al., 2010; de Pisapia et al., 2011; Reuss et al., 2011; Zhou and Davis, 2012), conflict detection/resolution (Ursu et al., 2009; D'Ostilio and Garraux, 2012) (but see Dehaene et al., 2003; Bruchmann et al., 2011), motivation (Pessiglione et al., 2007; Aarts et al., 2008; Custers and Aarts, 2010) and error detection (Nieuwenhuis et al., 2001; Hester et al., 2005; Klein et al., 2007; O'Connell et al., 2007; Belopolsky et al., 2008; Cohen et al., 2009; Pavone et al., 2009; Dhar et al., 2011) (but see Woodman, 2010). To illustrate, Lau and Passingham (2007) cued participants consciously to perform either a phonological or semantic judgment on an upcoming word. This conscious instruction cue was always preceded by a conscious or unconscious prime associated with the same or the alternative task (congruent vs. incongruent trials) (see also Mattler, 2003 for a behavioral version of this experiment). When participants were unconsciously primed to perform the phonological task, there was increased activity in a cortical network associated with this task (premotor cortex) and decreased activity in the cortical network associated with the semantic task (inferior frontal cortex and middle temporal gyrus), and vice versa. These results demonstrate that task-related neural networks, incorporating prefrontal cortex, can be modulated unconsciously. Further, the authors showed that unconscious primes triggered stronger activity in the dorsolateral prefrontal cortex compared to conscious primes, irrespective of the specific task being cued. Recently, Zhou and Davis (2012) went one step further and demonstrated that this effect was not caused by low-level perceptual priming and could still be observed when the unconscious cue was not part of the consciously instructed task-set.

Although it has repeatedly been observed that the strength of unconscious information processing increases considerably with practice and learning (Damian, 2001; van den Bussche et al., 2009; van Gaal et al., 2009), it has been shown that strong stimulus-response bindings are not a prerequisite for subliminal processing to occur (for a meta-analysis see van den Bussche et al., 2009). However, primes that are also included as targets ("repeated primes") have a stronger impact and might affect motor responses earlier (have a faster time-course) than primes that are not included as targets ("novel primes") (Finkbeiner and Friedman, 2011). In fact, also for higher-level cognitive control processes, such as response inhibition, stimulus-response mappings can be flexibly changed without abolishing unconscious priming effects. In a task in which a masked stimulus (diamond or square) could be associated with either a Go or No-Go response, but the specific mapping of stimuli onto these actions varied on a trial-by-trial basis (by virtue of a pre-cue), it was recently demonstrated that the same unconscious stimulus could have a substantially different effect on behavior and (prefrontal) brain activity depending on the rapidly changing task-context in which it was presented (Wokke et al., 2011).

In conclusion, several "high-level" (prefrontal) cognitive functions, such as response inhibition and task-switching, have been observed to be influenced and modulated by subliminal stimuli. These activations seem truly functional, because they are associated with behavioral indices of cognitive control. In the next section, we will discuss the influence of top-down factors (e.g., attention, task-set) on the extent of subliminal information processing and whether subliminal information can initiate top-down cognitive task-sets itself.

\section{CONSCIOUS AWARENESS AND TOP-DOWN COGNITIVE CONTROL}

Traditionally, it has been assumed that unconscious processes were rather automatic, inflexible, and independent of top-down cognitive control (see Hommel, 2007; Kiefer et al., 2012 for reviews). However, accumulating evidence shows that unconscious information processing is not fully automatic, but can be modulated by several top-down cognitive and attentional factors. Overall, the instructed task-set and subjects' strategy strongly affects the strength, direction and depth of subliminal information processing (Kunde et al., 2003; Greenwald et al., 2003; Ansorge and Neumann, 2005; Kiefer and Martens, 2010; Al-Janabi and Finkbeiner, 2011; O'Connor and Neill, 2011). For example, the top-down instructed task-set, e.g., either to read aloud a visible target word or to categorize it as representing natural or artificial objects, can change the processing route taken by an unconscious (masked) word preceding the target word (Nakamura et al., 2007). Along similar lines, Kiefer and Martens 
(2010) recently showed that the N400 ERP component to unrelated prime-target pairs (e.g., masked word "chair" followed by a visible target word "leaf"), compared to related prime-target pairs (e.g., masked word "chair" followed by visible target word "table"), was enhanced when a semantic task-set was induced by a visible cue presented immediately before each trial and was attenuated by a perceptual task-set (see also Martens et al., 2011). Further, attended subliminal stimuli have a stronger impact on behavior than unattended subliminal stimuli, and this is the case for spatial attention (Kentridge et al., 1999, 2004, 2008; Sumner et al., 2006; Bahrami et al., 2008a; Marzouki et al., 2008; Finkbeiner and Palermo, 2009), temporal attention (Naccache et al., 2002; Kiefer and Brendel, 2006; Fabre et al., 2007) and during attentional load (Bahrami et al., 2008b; Martens and Kiefer, 2009).

Task-relevant (attended) stimuli are processed stronger than task-irrelevant (unattended) stimuli, even when unconscious. Ansorge and Neumann (2005) showed that task-relevant prime features (e.g., shape) affected responses to the target only when the shape dimension was response relevant, but not when this feature was task-irrelevant, for example when the color of the target determined the required response (see also Tapia et al., 2010). We recently explored the role of task-relevance of subliminal information using EEG in a task in which subjects had to respond as fast as possible to a black Go annulus, unless it was preceded by a briefly presented gray circle (the no-go stimulus). Due to variations in the SOA between the No-Go circle and Go annulus, on some trials the No-Go circle was perceived consciously, whereas on others it was not. On the current trial, unconscious No-Go circles activated prefrontal control networks (van Gaal et al., 2008), and the extent to which correlated strongly with the amount of RT slowing to these stimuli. Crucially, exactly the same subliminal gray circle did not activate the PFC when it was task-irrelevant, but presented in a highly similar task-context (although it yielded similar early visual responses). This result highlights that the processing route taken by an unconscious stimulus strongly depends on task-relevance (and attention to the stimulus), and that task-irrelevant subliminal stimuli probably decay rapidly while progressing up in the cortical hierarchy. Recently, it has been observed that, under some conditions, cognitive control processes can still be influenced by subliminal stimuli presented outside the direct focus of spatial attention (Rahnev et al., 2012).

The role of attention and other top-down factors for unconscious information processing might depend on type of information to be processed. Recent research suggests that attention might be more crucial for "neutral" stimuli (e.g., numbers: Naccache et al., 2002) than for emotional, arousing or "evolutionary relevant" stimuli. To illustrate, Finkbeiner and Palermo (2009) have found that masked pictures of face stimuli produced priming regardless of whether they were spatially attended (however, this was not the case for subliminal eye-gaze cues: Al-Janabi and Finkbeiner, 2011). In contrast, other non-face stimuli (animals, vegetables) only produced subliminal priming when attended (see also Harry et al., 2012). However, although it seems that the threshold for conscious access is lower for emotional stimuli (Gaillard et al., 2006) and that these produce stronger priming
(Brooks et al., 2012), also emotional information processing does not seem to be fully automatic and is also modulated by top-down "attentional sensitization," at least to some extent (Kiefer et al., 2012). In fact, even when emotional pictures (e.g., faces) are presented fully consciously their depth and extent of processing seem to be facilitated by attentional factors (Pessoa et al., 2002, 2003).

Attention itself can also be attracted unconsciously (for review see Mulckhuyse and Theeuwes, 2010), for example by threatening (Lin et al., 2009), emotional (Vuilleumier and Schwartz, 2001; Brooks et al., 2012), erotic (Jiang et al., 2006), or socially relevant stimuli (Sato et al., 2007), but also by lower-level stimulus attributes, such as gamma flicker (Bauer et al., 2009) and stimulus orientation (Rajimerhr, 2004). Recently, it has been shown that individual differences in attentional bias to masked fearful faces are related to gray matter volume in the anterior cingulate cortex (Carlson et al., 2012), suggesting that these attentional effects are truly top-down mediated.

The literature reviewed above illustrates that consciously instructed task-sets and strategies as well as attentional factors strongly influence the processing of subliminal stimuli in various ways. At present, it is still an open and important question whether top-down task-sets can also be triggered by subliminal information. Several studies have reported so-called "top-down context effects." In these experiments, subjects generally perform a masked priming task consisting of congruent and incongruent prime-target pairs. The crucial manipulation in such experiments is the ratio of congruent and incongruent trials within experimental blocks. In blocks in which the prime direction does not predict the direction of the upcoming target (50\% congruent and $50 \%$ incongruent trials) subjects are generally faster to congruent than to incongruent trials. However, several experiments have consistently revealed that the impact of conflicting stimuli on behavior is larger when incongruent prime-target pairs are infrequent $(\sim 20 \%)$ compared to when these are frequent $(\sim 80 \%)$, at least when conflicting stimuli are presented consciously (for review see Desender and van den Bussche, 2012). In fact, the effect might even completely reverse in such a way that responses to incongruent prime-target pairs are faster than to congruent pairs (Merikle and Joordens, 1997; Daza et al., 2002), because subjects are able to strategically use the prime information to predict the upcoming target category. Even for conscious trials this might take some time ( $\sim 400 \mathrm{~ms})$, suggesting that these strategic effects take some time to build up (Ortells et al., 2003). These conscious strategic effects were recently only observed for spatially attended stimuli, but not for unattended ones (Ortells et al., 2011). At present it is still disputed whether such context effects depend on the conscious awareness of the primes, because several studies have reported an absence of congruency effects when the conflicting stimuli were presented subliminally (Merikle and Joordens, 1997; Daza et al., 2002; van den Bussche et al., 2008; Heinemann et al., 2009). However, other studies have shown that context effects also apply to unconscious prime stimuli (Jaskowski et al., 2003; Bodner and Masson, 2004; Wolbers et al., 2006; Klapp, 2007; Bodner and Mulji, 2010). Interestingly, these context effects initiated by subliminal primes might be related to increased connectivity between the pre-SMA and stimulus-related (LOC) and motor-related (putamen) brain areas (Wolbers et al., 2006), 
suggesting that the pre-SMA plays a role in the strategic control over the processing of subliminally presented conflicting stimuli.

Several authors have noted that it is important to examine whether these context effects are truly unconscious, at all processing levels, and which part of the effect might be explained by meta-cognitive (conscious) processes. For example, subjects might become aware of the increased error rate, experienced "difficulty" or "effort" on blocks with high numbers of conflicting trials and thereby might strategically adapt their response strategy or attentional focus (Jaskowski et al., 2003; Kinoshita et al., 2008, 2011, for a more extensive discussion of this issue see Desender and van den Bussche, 2012 and below). Therefore, it is still an open question whether top-down context effects can also be initiated by unconscious stimuli (Dehaene and Naccache, 2001).

Heinemann et al. (2009) studied the role of conflict awareness in a slightly different way, namely by examining the role of context on conflict frequency effects, also referred to as the context-specific proportion congruent effect (see also Crump et al., 2006). They performed a typical masked priming task in which subjects had to categorize target numbers as being larger or smaller than 5. A target was always preceded by a masked prime number that could be congruent or incongruent to the target. Crucially, just before the presentation of the prime-target pair they presented a colored rectangle at the background that determined the congruency context (the colored rectangle disappeared upon presentation of the response feedback). One color was consistently associated with a low interference context $(80 \%$ congruent trials, $20 \%$ incongruent trials), whereas another color was associated with a high interference context (20\% congruent trials, $80 \%$ incongruent trials). As predicted, for weakly masked primes (visible) the congruency effect (RT incongruent-RT congruent) was significantly smaller in the high interference context than in the low interference context (32 vs. $54 \mathrm{~ms}$ ). Crucially, they showed that these context-specific congruency effects were absent for strongly masked (poorly visible) trials. The authors concluded that context-specific congruency adaptation requires conscious representation of the conflicting information. Interestingly, previous work suggests that, even when using visible stimuli only, subjects do not have any explicit awareness of the congruency manipulation in similar tasks (Crump and Milliken, 2009). Therefore, it has been suggested that context-specific congruency effects might not depend on explicit knowledge of the congruency proportions, but might require sufficiently strong (i.e., conscious) representations of the prime, target and context (Kunde et al., 2012).

In a recent study, van Opstal et al. (2011a) took a somewhat different approach and demonstrated that context effects might indeed be initiated by subliminal primes. In their task, subjects had to indicate whether two target numbers (e.g., 3-3) were the same or different. These target numbers were always preceded by a masked (subliminal) prime. The crucial comparative prime consisted of a capital letter and a lower-case letter (A-a). In one experiment these primes were mixed with primes consisting of two completely different letters (a-D, the low-similarity context, Figure 2A), whereas in another experiment they were mixed with primes consisting of exactly the same letters ( $a-a$, the high-similarity context, Figure 2B). In the low-similarity context where a-A primes were relatively similar to a-a primes (compared to a-D primes), a-A primes facilitated a "same" response to the targets (Figure 2C). On the other hand, the same prime (a-A) presented in the high-similarity context (containing a-a

A Low Similarity Context (Van Opstal et al., 2010)

B High Similarity Context (current experiment)
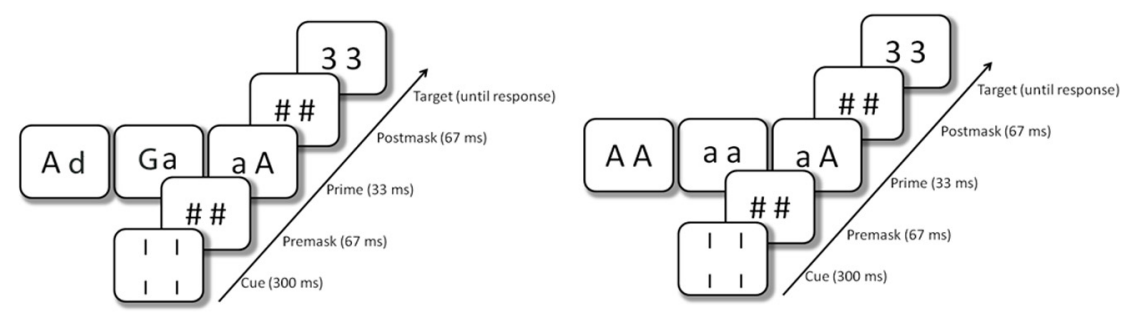

C

D

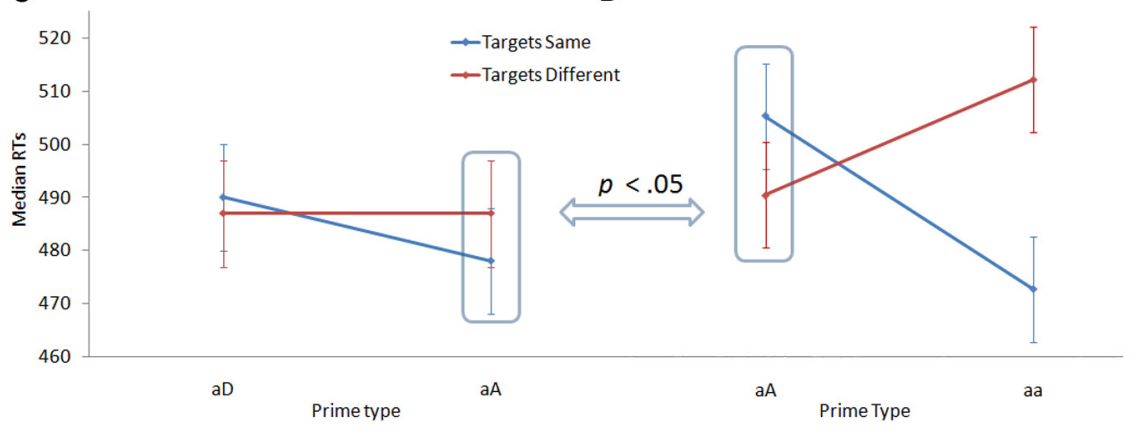

FIGURE 2 | (A,B) Task-set-up. (C,D) Response times for the low-similarity and high-similarity context for the different prime types and prime-target congruency. Adapted with permission from van Opstal et al. (2011a). 
primes) was relatively different and indeed facilitated a "different" response to the targets (Figure 2D). Importantly, RTs were equated across conditions and, therefore, could not (directly) explain the observed effects. This may be an important step in further pushing the boundaries of unconscious information processing and opens the possibility that also a top-down task-set may be enabled unconsciously (Dehaene and Naccache, 2001).

By now it is well established that subliminal information processing (e.g., its depth, extent, and direction) is influenced by several top-down cognitive functions, such as attention, task-set and strategy. However, whether top-down context effects themselves can be initiated or affected by subliminal stimuli is still under scrutiny (see also Kunde et al., 2012). In this respect, the underlying mechanisms, boundary conditions and role of awareness in blockwise congruency effects (Desender and van den Bussche, 2012) and context-specific proportion effects (Heinemann et al., 2009) are interesting avenues for future experimentation. Next, we will discuss another crucial and disputed aspect of subliminal information processing: its alleged short-lived nature.

\section{THE LIFE-TIME OF SUBLIMINAL INFORMATION PROCESSING}

The amount of time that unconscious information can influence cognitive processing is strongly debated. Typical masked priming studies have reported a sharp decrease in the processing of masked primes with the passage of time and it has been observed that the influence of unconscious stimuli disappears within approximately half a second (Greenwald et al., 1996; Mattler, 2005). Although this initial evidence strongly pointed into the direction of a severely limited duration of unconscious processes (see also Kunde, 2003), recent studies question this assumption and have shown subtle influences of subliminal information across relatively long periods of time.

A recent fMRI study showed strong and long-lasting effects of unconscious task-relevant stimuli that were used for instrumental conditioning (Pessiglione et al., 2008). Pessiglione and colleagues performed a study in which subjects had to learn stimulus-value associations for stimuli that were presented below the threshold of awareness because of pattern masking. Some masked cues were paired with monetary gains whereas others were coupled with monetary losses. Subjects performed a task in which they could opt for a safe choice that was never rewarded or punished, or they could opt for a risky choice that could be rewarded $(+\mathfrak{E} 1)$, punished $(-\mathfrak{E} 1)$, or remain neutral. Behaviorally, subjects chose the risky response more often following reward predictive (masked) cues compared to punishment predictive (masked) cues. Further, the effect was larger toward the end of the experiment after many trials had been presented. The implicit learning of cue-value associations was related to activation in the ventral striatum. Arguably, one of the most surprising and interesting aspects of these results was that the delay between the masked cue and the eventual decision could be up to $3 \mathrm{~s}$, suggesting a relatively long duration of unconscious information processing (although an RT analysis was not reported, precluding an analysis of which prime processing durations were driving the behavioral effect).

Other long-term subliminal effects were recently reported in various memory paradigms. Although consciousness and (working) memory seem intimately related (Dehaene and Naccache,
2001; Baars and Franklin, 2003), recent studies suggest that at least some components of memory might also operate outside of consciousness. In several experiments, Voss and colleagues demonstrated another form of memory, namely recognition memory, without explicit stimulus awareness (Voss et al., 2008; Voss and Paller, 2009). They used colorful complex geometric shapes (also referred to as "kaleidopscope images") that were shown in a learning phase and were tested in a recognition test afterwards (the test-set is relatively large and the stimuli are highly similar). When new and old items were presented simultaneously in the recognition phase, subjects often make correct forced-choice decisions about these images without any explicit recognition or subjective confidence; in fact, subjects typically felt they were merely guessing (see also Jeneson et al., 2010). Interestingly, subjects' guess responses were more likely to be accurate when the stimuli were initially presented during dividedattention than during full-attention in the study phase, and when subjects were encouraged to guess instead of encouraged responding confidently during the test phase. It seems that instructions that encourage guessing can facilitate responses based on rapid visual information processing, without competing (and distracting) influences from explicit retrieval processes (Voss and Paller, 2010).

Recently Soto et al. (2011) went one step further and specifically tested the relation between working memory and awareness (see also Hassin et al., 2009). They briefly presented either a Gabor cue $(16.7 \mathrm{~ms})$ with a specific orientation, or a blank screen, followed by a mask. After a retention interval (2-5s) a test Gabor stimulus was presented and subjects had to indicate whether the orientation of the masked Gabor cue was tilted clockwise or counter-clockwise with respect to the orientation of the target Gabor. Following this orientation response, subjects had to indicate their subjective awareness of the masked Gabor cue on a 4-point scale (ranging from $1=$ "did not see anything," to $4=$ "saw the stimulus and its orientation"). For subjectively invisible Gabor cues (all "1" responses) objective orientation comparisons with the target were above chance level (generally just above $55 \%$ in several experiments), even when a conscious or unconscious distractor Gabor was presented in the retention interval. Based on this, the authors concluded that "visual memory can encode, maintain and access unconscious items for explicit discrimination goals" (p. 913). In this experimental setup, the authors' interpretation relies on the assumption that the subjective awareness measure was sensitive enough to fully isolate unaware Gabor cues from (partly) aware Gabor cues. At present, this issue needs some further exploration (Overgaard et al., 2006; Block, 2011), mainly because subjects generally used the lower ends of the subjective awareness scale (55\% of the trials fell in category $1,34 \%$ in category $2,5 \%$ in category 3 and $6 \%$ in category 4) and because objective Gabor detection performance (compared to "nothing" trials) was above chance-level for all " 1 " responses $\left(d^{\prime}=0.297\right)$. However, if confirmed, the demonstration of unconscious working memory, resistant to distraction, may have large implications for neurobiological and cognitive theories of consciousness.

In all of the discussed studies so far the subliminal stimulus affected (behavioral) responses directly, on the current trial. 
However, longer-lasting trial-by-trial modulatory effects of subliminal stimuli are sometimes also reported, and the role of awareness in both cognitive processes might differ considerably (Dehaene and Naccache, 2001; Boy et al., 2010). Typical trial-by-trial modulations are the slowing of responses after errors (post-error slowing) and the reduction of conflict interference after high-conflict compared to low-conflict trials (conflict adaptation). These effects are generally thought to originate from increased prefrontal top-down control triggered by the error/conflict signal (Cohen et al., 2000; Botvinick et al., 2001; Ridderinkhof et al., 2004), although other interpretations have also been proposed (Hommel et al., 2002; Mayr et al., 2003; Notebaert et al., 2009; Schlaghecken and Martini, 2012). It is debated whether unconscious information can elicit strategic, trial-by-trial and long-lasting (top-down) modulations over subsequent stimulus processing (Desender and van den Bussche, 2012). We will discuss the potential role of awareness in conflict adaptation first (Greenwald et al., 1996; Kunde, 2003).

In a seminal study published in 1996, Greenwald and colleagues demonstrated that a subliminal prime-target pair (consisting of valenced words, e.g., bomb-kiss) leaves no "memory trace" that influences responding to the next prime-target pair (Greenwald et al., 1996). Some years later, Kunde (2003) came to the same conclusion. In his experiment, participants performed a speeded two-choice response to a target arrow that was preceded by a smaller arrow (the prime). Because the prime fitted within the contour of the target, the target functioned as a (metacontrast) mask and ensured that participants did not become aware of it when it was presented briefly $(14 \mathrm{~ms})$, but they did when it was presented somewhat longer $(126 \mathrm{~ms})$. Although in the masked conditions, the prime could not consciously be perceived, RTs were faster and subjects made fewer errors when the prime and target were congruent than when they were incongruent (i.e., an unconscious correspondence effect). In contrast to these sametrial effects, conflict adaptation (when the correspondence effect on trial $n$ is smaller when trials were preceded by an incongruent trial compared to a congruent trial on trial $n-1$, Gratton et al., 1992), was only the case when primes were presented consciously, and not when primes were presented subliminally.

In recent years, others have replicated these results using a variety of paradigms; conflict adaptation effects are fully abolished when the conflicting primes are strongly masked (Greenwald et al., 1996; Kunde, 2003; Frings and Wentura, 2008; Boy et al., 2010; Ansorge et al., 2011). However, in some recent studies conflict adaptation has been observed for masked prime stimuli, although the effect is generally small (Bodner and Mulji, 2010; van Gaal et al., 2010a; Francken et al., 2011). Recently, we have suggested that this discrepancy between studies might be due to the timing and the attentional engagement of the subject in between trials. At short trial intervals, the fleeting nature of the subliminal prime stimulus (Dehaene and Naccache, 2001) might cause the effects to dissappear easily, either by overall distraction or by the mere elapsing of time and strong attentional involvement might slow down this process somewhat (note that primes are always task-irrelevant in these tasks). In fact, this might also be the case for conscious stimuli, but at a slower pace (Danielmeier and Ullsperger, 2011; Egner et al., 2011). Recently, Desender and van den Bussche (2012) reviewed a large set of studies regarding the role of awareness in conflict adaptation and highlighted some alternative interpretations of conflict adaptation effects that were driven by subliminal stimuli. They reasoned that, although the stimulus itself might be strongly masked and, therefore, subliminal, the effect it has on behavior and cognition might become conscious and drive conflict adaption. Subjects might for example be able to monitor their RTs (Marti et al., 2011) and because responses to incongruent trials are generally slower than to congruent trials, subjects might become aware of the conflict or difficulty by this means. Recently, it has been observed that our "sense of control" is larger following congruent than incongruent trials (or when action selection is "smooth and easy") (Wenke et al., 2010). In the case of unconscious conflict, we might sense an increased difficulty that calls for an increase of our sense of control over behavior, leading to trial-by-trial behavioral adaptations, such as conflict adaptation and post-error slowing.

Neuroimaging has revealed that unnoticed errors do trigger some aspects of error monitoring, such as ACC activity and Error-related Negativity (ERN) ERP modulations, but not others, such as insula activation and Error Positivity (Pe) ERP modulations, although evidence is mixed (Nieuwenhuis et al., 2001; Hester et al., 2005; Overbeek et al., 2005; Klein et al., 2007; O'Connell et al., 2007; Pavone et al., 2009; Ullsperger et al., 2010; Woodman, 2010; Dhar et al., 2011). To examine the behavioral consequences of aware and unaware errors, research has focused mainly on post-error slowing: the behaviorally observed slowing that occurs after the commission of an error (compared to a correct response), potentially as a strategy to prevent future errors. It has been observed that unnoticed (or unconscious) errors sometimes elicit small post-error slowing effects (Cohen et al., 2009) whereas sometimes they do not (Nieuwenhuis et al., 2001; Endrass et al., 2007; Klein et al., 2007; van Gaal et al., 2009). Recently, we have explored the trial-by-trial effects of errors made to unconsciously presented stimuli (responses to subliminal No-Go stimuli) (Cohen et al., 2009). To do so, we separated responses on trials with a conscious No-Go circle (termed "conscious errors"), responses on trials with an unconscious No-Go circle ("unconscious errors"), and responses on go trials (Figure 3A). Subjects slowed down their responses considerably after conscious errors $(\sim 20 \mathrm{~ms})$ and very subtly (but significantly) after unconscious errors $(\sim 3 \mathrm{~ms})$. Spectral granger causality analyses revealed that conscious errors elicited top-down modulations from frontal electrodes to occipital electrodes leading up to the next trial (in the inter-trial-interval) (see also King et al., 2010 for error-related top-down modulations of motor and sensory regions using fMRI). Crucially, these top-down modulations were also observed after unconscious errors (Figure 3B), thus suggesting that unconscious events can elicit an "automatic" feedback loop in the absence of stimulus awareness. Importantly, in this task, RTs on the previous trial on which the unconscious error was made were equal, ruling out the possibility that these longer-lasting trial-by-trial effects were due to the conscious monitoring of RTs on the previous trials (Marti et al., 2011). However, whether these effects can be explained by other metacognitive processes such as experienced "effort" or "difficulty" is 


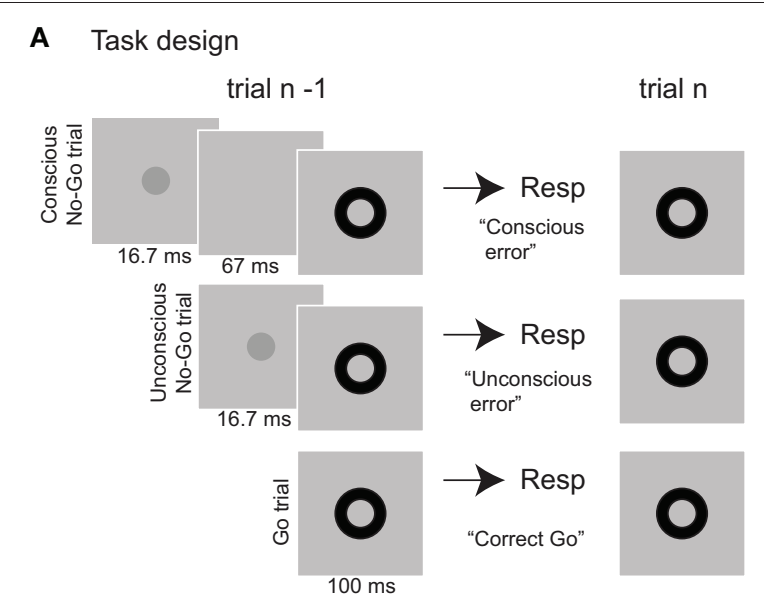

B Directional influences (spectral Granger causality) $\mathrm{MFC} \longrightarrow \mathrm{OCC}$
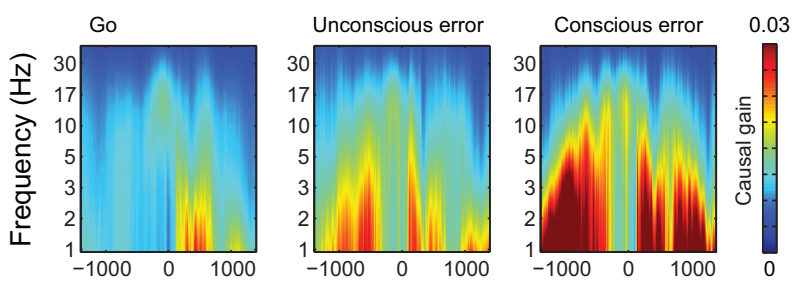

$\mathrm{MFC} \longrightarrow$ OCC (Unconscious error - Go)
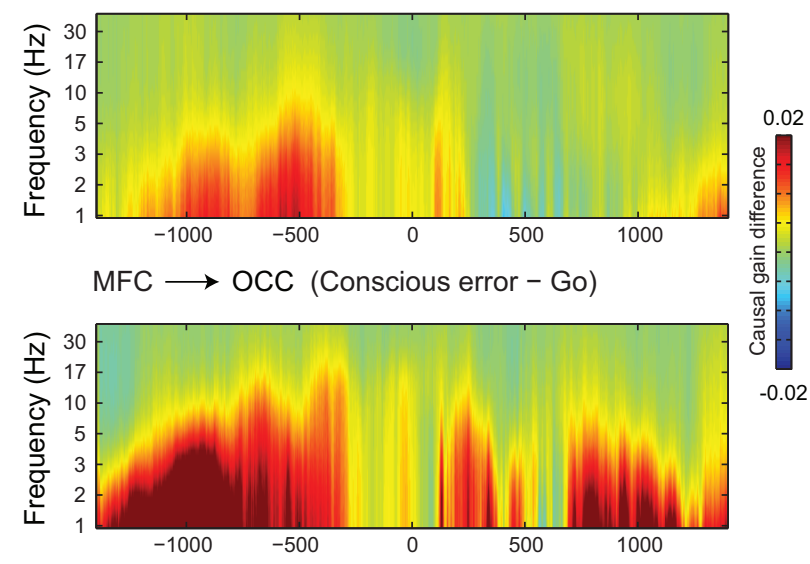

FIGURE 3 | (A) Task-set-up. (B) Response errors committed to trials containing a conscious No-Go signal and unconscious No-Go signal elicit long-lasting top-down influences from medial frontal (MFC) to occipital (OCC) regions (electrodes) in a broad frequency band $(\sim 1-12 \mathrm{~Hz})$, leading up to the next trial. Effects for each of the three conditions separately (upper panel) and the difference plots (lower panel) are shown. Time 0 is the presentation of the Go-signal (black annulus). Plots are separated by the significance of the event on the previous trial (correct Go response, conscious error, or unconscious error). Adapted with permission from Cohen et al. (2009).

an avenue for future research (Wenke et al., 2010; Desender and van den Bussche, 2012). It is interesting to note that although unaware errors seem to elicit relatively strong neural activity on the current trial (mainly in the medial frontal cortex) which are accompanied and followed by short-lived increases in top-down interactions that might drive automatic behavioral adaptations at relatively short inter-trial intervals (Cohen et al., 2009), longterm behavioral adaptations on the next trial are generally weak. Therefore, although speculative, error awareness might be beneficial for broader longer-lasting control adaptations that might be associated with activation in the anterior insula (Ullsperger et al., 2010) and reflected in the (late part) of the Pe ERP component (Nieuwenhuis et al., 2001; Endrass et al., 2007).

Overall, the discussed studies suggest that, under some specific conditions, subliminal information might durably affect behavior and brain activity, sometimes even beyond several seconds (Gaillard et al., 2007; Pessiglione et al., 2008; Capa et al., 2010; Soto et al., 2011). Occasionally indirect consequences of subliminal (affective) information can be measured for several minutes (Gaillard et al., 2007) and up to even as long as $24 \mathrm{~h}$ after its presentation (Sweeny et al., 2009). Although some of these effects may be caused by a form of learning and, therefore, synaptic changes rather than long-lasting (and active) subliminal activation (Gaillard et al., 2007), other effects might be truly mediated by the active maintenance of information across several seconds of time. In the next section, we will focus on the role of stimulus awareness in the integration of information across time and space.

\section{CONSCIOUSNESS AND DECISION-MAKING}

The literature we reviewed so far shows that unconscious information can affect high-level processes, and might even act on aspects of cognitive control and (working) memory. Lastly, we will discuss studies that investigated whether and how unconscious information can be accumulated across time or space for perception and decision-making. Active information integration is considered one of the hallmarks of consciousness by many contemporary models of consciousness (Tononi and Edelman, 1998; Engel and Singer, 2001; Crick and Koch, 2003; Baars, 2005; Seth et al., 2008).

Several recent studies have observed that, under some conditions, subliminal information can be accumulated and integrated spatially across the visual field (van Opstal et al., 2011b). In one of van Opstal's experiments, subjects were presented with 4 spatially separated numbers (primes) that were preceded and followed by masks that prevented conscious perception of the primes. A target, also consisting of four digits, followed the prime rapidly and subjects had to indicate whether the mean of the 4 target digits was more or less than 5. Interestingly, the mean of the subliminal primes affected RTs and accuracy to target responses, suggesting that so-called "ensemble statistics" might be extracted unconsciously. Other recent evidence also suggests that multiple unconscious stimuli can be integrated across space, for example when visual scenes are presented in the absence of awareness because of continuous flash suppression (Mudrik et al., 2011). Also, expert chess players (but not novices) are able to extract whether a subliminal (masked) simplified chess configuration entails a checking configuration or not. However, this was only the case for highly familiar chess configurations, and was not present in a task that required the integration of local features, namely field color (black or white) and chess piece (rook or knight). 
This suggests that experts have created chunks of common chess configurations in long-term memory (which novices have not) and, therefore, that they might not actively have to integrate individual stimulus features (Kiesel et al., 2009). Generally, the extent of practice might be crucial and partly explain why evidence in the field is somewhat mixed. Others have shown that the integration of local features into global shapes does require stimulus awareness, for example when stimuli are rendered invisible due to counter-phase flickering of stimulus contrast (Schwarzkopf and Rees, 2010).

Unconscious information also seems to be integrated or accumulated across time, at least to some degree. Previous studies have shown that subliminal information can be accumulated linearly over a few hundreds of milliseconds (Jaskowski et al., 2003; Vorberg et al., 2003; Wentura and Frings, 2005; Del Cul et al., 2007; Frings et al., 2008). For example, Jaskowski et al. (2003) nicely showed that increasing the number of primes presented before a target increases the behavioral priming effect. In their task, subjects were required to respond to the spatial location of a square with horizontal gaps presented together with a square without such gaps. Targets could be preceded by either 1, 2, 3 or 4 primes (presented for $35 \mathrm{~ms}$ each) which were smaller copies of the target. Because the squares in every next stimulus were slightly larger than the previous ones, they masked the preceding stimulus. They showed that each of the 4 primes had an influence on the response to target, and that with increasing number of primes the priming effect was larger. Similarly, Vorberg et al. (2003) have shown that when the time between prime and target is increased (from 14 to $86 \mathrm{~ms}$ in steps of $14 \mathrm{~ms}$ ) the behavioral priming effect increases monotonically. Subjects had to respond to the direction of a metacontrast target arrow that was preceded by a smaller version of it. Importantly, because the stimuli were presented outside the focus of attention (below and above fixation), there were no SOA-related changes in prime awareness (see also Schmidt et al., 2010). Together, these results suggest that subliminal information can be accumulated over short periods of time $(<150 \mathrm{~ms})$ and increasingly impact behavior.

However, while the accumulation of information may be possible irrespective of the level of awareness over short periods of time, recent studies have shown that awareness might play an important role when the time across which information has to be accumulated is increased. de Lange et al. (2011) performed a task in which subjects had to accumulate multiple pieces of evidence across $1.5 \mathrm{~s}$. On each trial, subjects were presented a stream of five arrows, each of which could point to the left or right with equal probability. They had to quickly decide on the direction of the majority of arrows, guessing if necessary (Figure 4A). The strength of the evidence could range from one (low evidence, e.g., two left and three right arrows) to five (high evidence, e.g., five right arrows). The visibility of the arrows was manipulated by masking them with an effective metacontrast mask leading to arrows near the threshold of awareness (low visibility condition) or with an equiluminant but less effective "pseudo" mask (leading to high visibility). On each trial, all arrows were either of low- or high visibility. Qualitative differences in perception were confirmed by objective as well as subjective discrimination measurements (leading to low vs. high visibility arrows, instead of conscious vs. unconscious arrows). Importantly, stimulus and mask duration were identical for both conditions, which allowed the comparison of behavioral performance of evidence accumulation (and the underlying neural responses) without confounding stimulus visibility with basic task parameters (e.g., signal strength) (Lau, 2008; Francken et al., 2011). Behaviorally, subjects were able to accumulate evidence

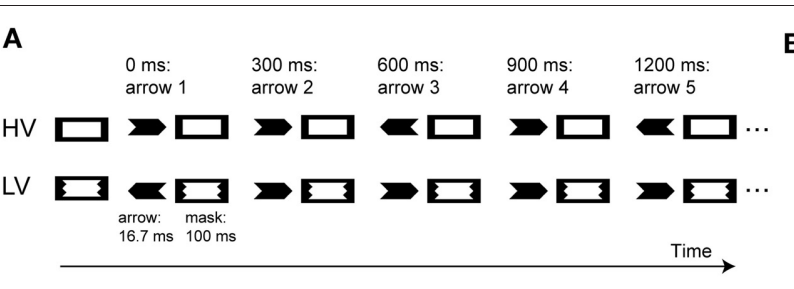

C

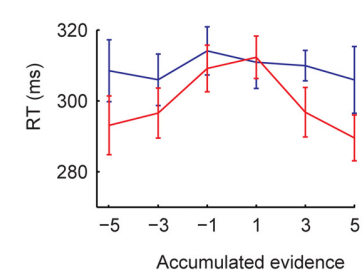

D

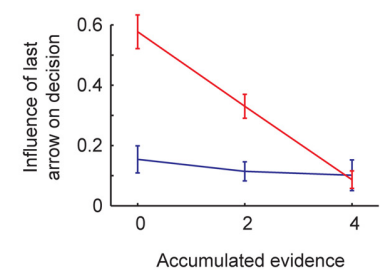

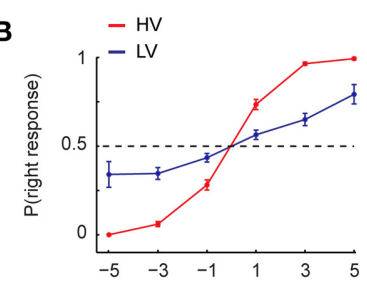

Accumulated evidence

E

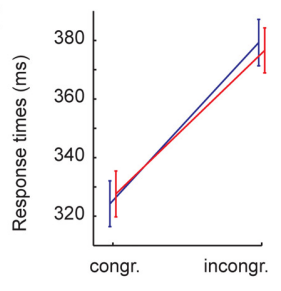

FIGURE 4 | (A) Task-set-up. (B) Decision-making performance as a function of accumulated evidence. Negative and positive numbers denote evidence for a left- and right-hand response, respectively, (number of right-pointing arrows minus number of left-pointing arrows). (C) Reaction times as a function of accumulated evidence. (D) Influence of the last arrow on the final decision as a function of the amount of previously accumulated evidence. (E) Priming strength of single high visibility or low visibility arrow as measured in a distinct masked priming task, in terms of response times. $\mathrm{HV}$, high visibility condition; LV, low visibility condition. Adapted with permission from de Lange et al. (2011). 
over time for both visibility conditions (Figure 4B). However, there were marked qualitative differences in how information was accumulated for the different levels of awareness. First, decisionmaking speed was modulated by the amount of accumulated evidence, but only for high-visible stimuli (Figure 4C). Second, once enough evidence had been gathered, participants strategically reduced the impact of new incoming stimuli (Figure 4D). Crucially, by using the same stimulus parameters but now in a masked priming task, it was observed that the amount of bottomup information provided by the arrows was the same for both conditions, as reflected in an equal size of the behavioral priming effect for both visibility conditions (Figure 4E). Thus, although unconscious evidence may be accumulated in a linear fashion, i.e., adding and subtracting new information without any regard to the history of prior accumulated evidence, non-linearities in evidence accumulation (for example, reducing the weight of new information under conditions of high certainty, Kiani et al., 2008; de Lange et al., 2010) may be present only for fully consciously perceived information. This qualitative difference (linear vs. nonlinear integration) was also observed in concurrently measured neural recordings: occipito-parietal regions that were involved in the accumulation of the sensory evidence showed a "linear" stereotypic response when presented with near-threshold information, but modulated their activity strategically during the task for clearly visible information. These results suggest that the level of awareness of information changes decision-making: while accumulation of evidence is already possible for low visibility information, high visibility allows evidence to be accumulated up to a much higher-level, leading to important changes in strategic top-down decision-making.

Similarly, Sackur and Dehaene (2009) demonstrated a qualitative processing difference as a function of stimulus awareness when studying sequential two-step arithmetic tasks with masked and visible digits. In their task, participants were instructed to add/subtract 2 from one masked or unmasked number (numbers were part of a restricted set: $2,4,6,8)$. Thereafter, subjects were required to indicate whether the outcome of this first operation was larger or smaller than 5. Interestingly, subjects were only able to perform a "chained task" of addition followed by comparison when the target digits were presented consciously, but not when they were presented subliminally. However, they could perform each individual computation above chance when the digits were presented subliminally (see also Garcia-Orza et al., 2009; Ric and Muller, in press). The authors have suggested that this qualitative difference can be explained by assuming that subliminal digits do not yield enough evidence to reach a threshold for the first computational step of the chained task and that this did not allow subjects to go past the first processing stage and deploy further strategies.

Bijleveld et al. (2010) reported an interesting related observation. They presented subjects with a poorly or strongly masked high- or low-reward cue (50 cents or 1 cent, respectively) that was quickly followed by a simple mathematical operation (e.g., $3+5+9=16$ ). Subjects had to indicate whether the expression was true or not. Two manipulations were crucial: (1) only correct responses were rewarded, and (2) on each trial the anticipated reward declined with time. They showed that subliminal high-reward cues (compared to low-reward cues) sped up the time people took to perform the mathematical operation, probably reflecting the increased investment of effort, but did not change the overall accuracy of participants' responses. In contrast, conscious high-reward cues (compared to low-reward cues) slowed down the time to perform the computation, but crucially, with the benefit of increasing the overall accuracy of the responses. In a second experiment, they showed that conscious and unconscious reward cues both elicit increases in effort only (speeding of responses), when the possibility to change the speed-accuracy balance is eliminated. Therefore, valuable rewards seem to enhance the effort put in a task at hand irrespective of the awareness of the reward (see also Pessiglione et al., 2007). However, the authors concluded that conscious rewards might impact the balance between speed and accuracy (preferring accuracy over speed), whereas unconscious reward cues do not, thereby providing a qualitative difference between the pursuit of rewards of which one is conscious vs. unconscious.

Although the sequential and spatial integration of multiple elements was generally considered a hallmark of consciousness, these recent results challenge that assumption and showed that some parts of this integration process might also operate outside of awareness. Further, it seems that, at least under some conditions, awareness is beneficial for enabling strategic changes in decision-making (see below for a more extensive discussion on why this might be the case).

\section{CONCLUSIONS, OPEN QUESTIONS AND FUTURE DIRECTIONS}

In this article, we have reviewed recent studies that have focused on the complexity and strength of unconscious information processing in relation to cognitive control (e.g., response inhibition, conflict resolution, and task-switching), the life-time of information maintenance (e.g., working memory, recognition memory) and the possibility to integrate multiple pieces of information across space and time. Unconscious information has been shown to affect various perceptual and high-level cognitive functions and the associated brain areas, including prefrontal cortex. In some cases, unconscious information has been observed to affect behavior and brain activity for relatively long periods of time. Overall, these recent results highlight the power of unconscious information processing, going beyond specific expectations formulated in traditional theoretical models of consciousness and the cognitive functions thought to require consciousness (for reviews see Umilta, 1988; Dehaene and Naccache, 2001; Jack and Shallice, 2001; Mayr, 2004; Hommel, 2007).

Based on this, one can conclude that the potential function of consciousness might not be related to the initiation of cognitive control functions by specific stimuli that signal the need for increased control (e.g., stop-signals, task-switching cues). These cognitive control operations are probably triggered by a fast feedforward, and unconscious, early sweep of information processing that reaches even regions in the prefrontal cortex (van Gaal and Lamme, in press). This unconscious fast feedforward sweep can directly affect (the speed of) ongoing cognitive processes. However, recent evidence also points out interesting dissociations between conscious and unconscious information 
processing when it comes to the duration, the flexibility, and the strategic use of information for complex operations and decision-making (Sackur and Dehaene, 2009; de Lange et al., 2011). Although recent evidence has clearly pushed the boundaries regarding the duration of unconscious effects, the general observation is that unconscious events are much less able to elicit (long-term) future behavioral adaptations than conscious events (e.g., post-error slowing, conflict adaptation). Why might this be the case? Theoretical models of consciousness suggest that conscious awareness is related to long-lasting recurrent interactions between (distant) brain regions (Lamme, 2006; Dehaene and Changeux, 2011). This might enable the exchange of information between several spatially separated cognitive modules, which seems to break the automaticity of information processing (Sackur and Dehaene, 2009). Awareness might be beneficial for enabling flexible and durable information processing strategies that are not directly triggered by a specific stimulus, for example when information has to be integrated across longer periods of time to bias information acquisition (de Lange et al., 2011) or signal the need for performance adjustments (Desender and van den Bussche, 2012). Recently, Kunde et al. (2012) suggested that awareness might be dispensable when cognitive control is signaled explicitly (by specific control-eliciting stimuli) but not when it has to be inferred implicitly (by the context, or history of events). This may prove to be a very useful and plausible distinction and needs further experimentation and exploration. Especially, the boundary conditions of implicitly signaled cognitive control are a promising avenue for future research and might clarify why unconsciously signaled (implicit) control operations are observed in some occasions but not in others.

At present, we believe that two aspects of subliminal information processing deserve more attention in future work, namely the role of task-relevance of unconscious information and the

\section{REFERENCES}

Aarts, H., Custers, R., and Marien, H. (2008). Preparing and motivating behavior outside of awareness. Science 319, 1639-1639.

Al-Janabi, S., and Finkbeiner, M. (2011). Effective processing of masked eye gaze requires volitional control. Exp. Brain Res. 216, 433-443.

Ansorge, U., Fuchs, I., Khalid, S., and Kunde, W. (2011). No conflict control in the absence of awareness. Psychol. Res. 5, 351-365.

Ansorge, U., and Neumann, O. (2005). Intentions determine the effect of invisible metacontrast-masked primes: evidence for top-down contingencies in a peripheral cuing task. J. Exp. Psychol. Hum. Percept. Perform. 31, 762-777.

Aron, A. R. (2007). The neural basis of inhibition in cognitive control. Neuroscientist 13, 214-228.

Aron, A. R., Schlaghecken, F., Fletcher, P. C., Bullmore, E. T., Eimer, M.,
Barker, R., Sahakian, B. J., and Robbins, T. W. (2003). Inhibition of subliminally primed responses is mediated by the caudate and thalamus: evidence from functional MRI and Huntington's disease. Brain 126, 713-723.

Baars, B. J. (2005). Global workspace theory of consciousness: toward a cognitive neuroscience of human experience. Prog. Brain Res. 150, 45-53.

Baars, B. J., and Franklin, S. (2003). How conscious experience and working memory interact. Trends Cogn. Sci. 7, 166-172.

Bahrami, B., Carmel, D., Walsh, V., Rees, G., and Lavie, N. (2008a). Spatial attention can modulate unconscious orientation processing. Perception 37, 1520-1528.

Bahrami, B., Carmel, D., Walsh, V., Rees, G., and Lavie, N. (2008b). Unconscious orientation processing depends on perceptual load. J. Vis. 8, 12.1-12.10.

potential source of some of the subliminally triggered effects. Typically, masked priming studies have used subliminal stimuli that should be (actively) ignored for optimal task performance (e.g., Dehaene et al., 1998; Kunde, 2003; Vorberg et al., 2003). However, as discussed above, it seems that task-relevant unconscious information has much stronger and longer-lasting effects on behavior and brain activity than task-irrelevant information (e.g., Ansorge and Neumann, 2005; Pessiglione et al., 2008; van Gaal et al., 2008; Soto et al., 2011), which might explain part of the discrepancy in the overall findings in the field. More generally, the significance of the unconscious events seems a crucial factor, but at this point, future studies are needed to specifically test this prediction.

Second, recent evidence suggests that some trial-by-trial effects can be triggered by unconsciously presented stimuli, although some of the effects are limited and are generally relatively small. In some cases, these complex and relatively long-lasting effects (e.g., congruency effects, trial-by-trial modulations) might be explained by meta-cognitive effects, which need to be carefully controlled for to foster interpretation about the source of the observed "unconscious" phenomena (Jaskowski et al., 2003; Kinoshita et al., 2008; Wenke et al., 2010; see Desender and van den Bussche, 2012 for an extensive review on this issue). One of the main goals of future research could be to test whether and to what extent these long-term effects are caused by subjects becoming meta-cognitively aware of the conflict/error signals, although they are unaware of the initial source of it.

\section{FUNDING}

This work was supported by the Netherlands Organization for Scientific Research (NWO-Rubicon awarded to Simon van Gaal; NWO-VENI awarded to Floris P. de Lange; NWO-VIDI awarded to Michael X Cohen).

Bargh, J. A., and Morsella, E. (2008) The unconscious mind. Perspect. Psychol. Sci. 3, 73-79.

Bauer, F., Cheadle, S. W., Parton, A. Muller, H. J., and Usher, M. (2009). Gamma flicker triggers attentional selection without awareness. Proc. Natl. Acad. Sci. U.S.A. 106, 1666-1671.

Belopolsky, A. V., Kramer, A. F., and Theeuwes, J. (2008). The role of awareness in processing of oculomotor capture: evidence from event-related potentials. J. Cogn. Neurosci. 20, 2285-2297.

Bijleveld, E., Custers, R., and Aarts, H. (2010). Unconscious reward cues increase invested effort, but do not change speed-accuracy trade-offs. Cognition 115, 330-335.

Block, N. (2011). Perceptual consciousness overflows cognitive access. Trends Cogn. Sci. 15, 567-575.

Bodner, G. E., and Masson, M. E. (2004). Beyond binary judgments: prime validity modulates masked repetition priming in the naming task. Mem. Cogn. 32, $1-11$.

Bodner, G. E., and Mulji, R. (2010). Prime proportion affects masked priming of fixed and free-choice responses. Exp. Psychol. 57, 360-366.

Botvinick, M. M., Braver, T. S., Barch, D. M., Carter, C. S., and Cohen, J. D. (2001). Conflict monitoring and cognitive control. Psychol. Rev. 108, 624-652.

Boy, F., Husain, M., and Sumner, P. (2010). Unconscious inhibition separates two forms of cognitive control. Proc. Natl. Acad. Sci. U.S.A. 107, 11134-11139.

Brooks, S. J., Savov, V., Allzen, E., Benedict, C., Fredriksson, R., and Schioth, H. B. (2012). Exposure to subliminal arousing stimuli induces robust activation in the amygdala, hippocampus, anterior cingulate, insular cortex and primary visual cortex: a systematic meta-analysis 
of fMRI studies. Neuroimage 59, 2962-2973.

Bruchmann, M., Herper, K., Konrad, C., Pantev, C., and Huster, R. J. (2011). Individualized EEG source reconstruction of Stroop interference with masked color words. Neuroimage 49, 1800-1809.

Capa, R. L., Bustin, G. M., Cleeremans, A., and Hansenne, M. (2011). Conscious and unconscious reward cues can affect a critical component of executive control. Exp. Psychol. $58,370-375$.

Capa, R. L., Cleeremans, A., Bustin, G. M., and Hansenne, M. (2010). Long-lasting effect of subliminal processes on cardiovascular responses and performance. Int. J. Psychophysiol. 81, 22-30.

Carlson, J. M., Beacher, F., Reinke, K. S., Habib, R., Harmon-Jones, E., Mujica-Parodi, L. R., and Hajcak, G. (2012). Nonconscious attention bias to threat is correlated with anterior cingulate cortex gray matter volume: a voxel-based morphometry result and replication. Neuroimage 59, 1713-1718.

Cohen, J. D., Botvinick, M., and Carter, C. S. (2000). Anterior cingulate and prefrontal cortex: who's in control? Nat. Neurosci. 3, 421-423.

Cohen, M. X., van Gaal, S., Ridderinkhof, K. R., and Lamme, V. A. F. (2009). Unconscious errors enhance prefrontaloccipital oscillatory synchrony. Front. Hum. Neurosci. 3:54. doi: 10.3389/neuro.09.054.2009

Crick, F., and Koch, C. (2003). A framework for consciousness. Nat. Neurosci. 6, 119-126.

Crump, M. J., Gong, Z., and Milliken, B. (2006). The context-specific proportion congruent Stroop effect: location as a contextual cue. Psychon. Bull. Rev. 13, 316-321.

Crump, M. J., and Milliken, B. (2009). The flexibility of context-specific control: evidence for context-driven generalization of item-specific control settings. Q. J. Exp. Psychol. (Hove) 62, 1523-1532.

Custers, R., and Aarts, H. (2005). Positive affect as implicit motivator: on the nonconscious operation of behavioral goals. J. Pers. Soc. Psychol. $89,129-142$.

Custers, R., and Aarts, H. (2010). The unconscious will: how the pursuit of goals operates outside of conscious awareness. Science 329, 47-50.

D'Ostilio, K., and Garraux, G. (2012). Dissociation between unconscious motor response facilitation and conflict in medial frontal areas. Eur. J. Neurosci. 35, 332-340.
Damian, M. F. (2001). Congruity effects evoked by subliminally presented primes: automaticity rather than semantic processing. J. Exp. Psychol. Hum. Percept. Perform. 27, 154-165. Danielmeier, C., and Ullsperger, M. (2011). Post-error adjustments. Front. Psychol. 2:233. doi: 10.3389/ fpsyg.2011.00233

Daza, M. T., Ortells, J. J., and Fox, E. (2002). Perception without awareness: further evidence from a Stroop priming task. Percept. Psychophys. 64, 1316-1324.

de Pisapia, N., Turatto, M., Lin, P., Jovicich, J., and Caramazza, A. (2011). Unconscious priming instructions modulate activity in default and executive networks of the human brain. Cereb. Cortex 3 , 639-649.

Dehaene, S., Artiges, E., Naccache, L., Martelli, C., Viard, A., Schurhoff, F., Recasens, C., Martinot, M. L. P., Leboyer, M., and Martinot, J.L. (2003). Conscious and subliminal conflicts in normal subjects and patients with schizophrenia: the role of the anterior cingulate. Proc. Natl. Acad. Sci. U.S.A. 100, 13722-13727.

Dehaene, S., Changeux, J.-P., Naccache, L., Le Clec'H, G., Koechlin, E. Mueller, M., Dehaene-Lambertz, G., van de Moortele, P.-F., and Le Bihan, D. (1998). Imaging unconscious semantic priming. Nature 395, 597-600.

Dehaene, S., and Changeux, J. P. (2011). Experimental and theoretical approaches to conscious processing. Neuron 70, 200-227.

Dehaene, S., and Naccache, L. (2001). Towards a cognitive neuroscience of consciousness: basic evidence and a workspace framework. Cognition 79, 1-37.

de Lange, F. P., Jensen, O., and Dehaene, S. (2010). Accumulation of evidence during sequential decision making: the importance of top-down factors. J. Neurosci. 30, 731-738.

de Lange, F. P., van Gaal, S., Lamme, V. A., and Dehaene, S. (2011). How awareness changes the relative weights of evidence during human decision-making. PLoS Biol. 9:e1001203. doi: 10.1371/journal. pbio. 1001203

Del Cul, A., Baillet, S., and Dehaene, S. (2007). Brain dynamics underlying the nonlinear threshold for access to consciousness. PLoS Biol. 5:e260. doi: 10.1371/journal.pbio.0050260

Desender, K., and van den Bussche, E. (2012). Is consciousness necessary for conflict adaptation? A state of the art. Front. Hum. Neurosci. 6:3. doi: 10.3389/fnhum.2012.00003
Dhar, M., Wiersema, J. R., and Pourtois, G. (2011). Cascade of neural events leading from error commission to subsequent awareness revealed using EEG source imaging. PLoS One 6:e19578. doi: 10.1371/journal.pone.0019578

Egner, T., Ely, S., and Grinband, J. (2011). Going, going, gone: characterizing the time-course of congruency sequence effects. Front. Psychol. 1:154. doi: 10.3389/fpsyg 2010.00154

Eimer, M. (1999). Facilitatory and inhibitory effects of masked prime stimuli on motor activation and behavioural performance. Acto Psychol. (Amst.) 101, 293-313.

Eimer, M., Maravita, A., van Velzen, J., Husain, M., and Driver, J. (2002). The electrophysiology of tactile extinction: ERP correlates of unconscious somatosensory processing. Neuropsychologia 40, 2438-2447.

Eimer, M., and Schlaghecken, F. (1998). Effects of masked stimuli on motor activation: behavioral and electrophysiological evidence. J. Exp. Psychol. Hum. Percept. Perform. 24, 1737-1747.

Endrass, T., Reuter, B., and Kathmann, N. (2007). ERP correlates of conscious error recognition: aware and unaware errors in an antisaccade task. Eur. J. Neurosci. 26, 1714-1720.

Engel, A. K., and Singer, W. (2001). Temporal binding and the neural correlates of sensory awareness. Trends Cogn. Sci. 5, 16-25.

Fabre, L., Lemaire, P., and Grainger, J. (2007). Attentional modulation of masked repetition and categorical priming in young and older adults. Cognition 105, 513-532.

Fang, F., and He, S. (2005). Cortical responses to invisible objects in the human dorsal and ventral pathways. Nat. Neurosci. 8, 1380-1385.

Finkbeiner, M., and Friedman, J. (2011). The flexibility of nonconsciously deployed cognitive processes: evidence from masked congruence priming. PLoS One 6:e17095. doi: 10.1371/journal. pone.0017095

Finkbeiner, M., and Palermo, R. (2009). The role of spatial attention in nonconscious processing: a comparison of face and nonface stimuli. Psychol. Sci. 20, 42-51.

Francken, J. C., van Gaal, S., and de Lange, F. P. (2011). Immediate and long-term priming effects are independent of prime awareness. Conscious. Cogn. 20, 1793-1800.

Frings, C., Bermeitinger, C., and Wentura, D. (2008). Centersurround or spreading inhibition: which mechanism caused the negative effect from repeated masked semantic primes? Exp. Psychol. 55, 234-242.

Frings, C., and Wentura, D. (2008). Trial-by-trial effects in the affective priming paradigm. Acta Psychol. (Amst.) 128, 318-323.

Gaillard, R., Cohen, L., Adam, C., Clemenceau, S., Hasboun, D., Baulac, M., Willer, J. C., Dehaene, S., and Naccache, L. (2007). Subliminal words durably affect neuronal activity. Neuroreport 18, 1527-1531.

Gaillard, R., Del Cul, A., Naccache, L., Vinckier, F., Cohen, L., and Dehaene, S. (2006). Nonconscious semantic processing of emotional words modulates conscious acces. Proc. Natl. Acad. Sci. U.S.A. 103, 7524-7529.

Garcia-Orza, J., Damas-Lopez, J., Matas, A., and Rodriguez, J. M. (2009). " 2 × 3" primes naming " 6 ": evidence from masked priming. Atten. Percept. Psychophys. 71, 471-480.

Gratton, G., Coles, M. G., and Donchin, E. (1992). Optimizing the use of information: strategic control of activation of responses. J. Exp. Psychol. Gen. 121, 480-506.

Greenwald, A. G., Abrams, R. L., Naccache, L., and Dehaene, S. (2003). Long-term semantic memory versus contextual memory in unconscious number processing. J. Exp. Psychol. Learn. Mem. Cogn. 29, 235-247.

Greenwald, A. G., Draine, S. C., and Abrams, R. L. (1996). Three cognitive markers of unconscious semantic activation. Science 273, 1699-1702

Harry, B., Davis, C., and Kim, J. (2012). Subliminal acces to face representations does not rely on attention. Conscious. Cogn. 21, 573-583.

Hassin, R. R., Bargh, J. A., Engell, A. D., and McCulloch, K. C. (2009). Implicit working memory. Conscious. Cogn. 18, 665-678.

Heinemann, A., Kunde, W., and Kiesel, A. (2009). Context-specific primecongruency effects: on the role of conscious stimulus representations for cognitive control. Conscious. Cogn. 18, 966-976.

Hester, R., Foxe, J. J., Molholm, S., Shpaner, M., and Garavan, H. (2005). Neural mechanisms involved in error processing: a comparison of errors made with and without awareness. Neuroimage 27, 602-608.

Hommel, B. (2007). Consciousness and control: not identical twins. J. Conscious. Stud. 14, 155-167. 
Hommel, B., Ridderinkhof, K. R., and Theeuwes, J. (2002). Cognitive control of attention and action: issues and trends. Psychol. Res. 66, 215-219.

Hughes, G., Velmans, M., and de Fockert, J. (2009). Unconscious priming of a no-go response. Psychophysiology 46, 1258-1269.

Jack, A. I., and Shallice, T. (2001). Introspective physicalism as an approach to the science of consciousness. Cognition 79, 161-196.

Jaskowski, P., Skalska, B., and Verleger, R. (2003). How the self controls its "automatic pilot" when processing subliminal information. J. Cogn. Neurosci. 15, 911-920.

Jaskowski, P., and PrzekorackaKrawczyk, A. (2005). On the role of mask structure in subliminal priming. Acta Neurobiol. Exp. (Wars) 65, 409-417.

Jeneson, A., Kirwan, C. B., and Squire, L. R. (2010). Recognition without awareness: an elusive phenomenon. Learn. Mem. 17, 454-459.

Jiang, Y., Costello, P., Fang, F., Huang, M., and He, S. (2006). A gender- and sexual orientation-dependent spatial attentional effect of invisible images. Proc. Natl. Acad. Sci. U.S.A. 103, 17048-17052.

Kentridge, R. W., Heywood, C. A., and Weiskrantz, L. (1999). Attention without awareness in blindsight. Proc. Biol. Sci. 266, 1805-1811.

Kentridge, R. W., Heywood, C. A., and Weiskrantz, L. (2004). Spatial attention speeds discrimination without awareness in blindsight. Neuropsychologia 42, 831-835.

Kentridge, R. W., Nijboer, T. C., and Heywood, C. A. (2008). Attended but unseen: visual attention is not sufficient for visual awareness. Neuropsychologia 46, 864-869.

Kiani, R., Hanks, T. D., and Shadlen, M. N. (2008). Bounded integration in parietal cortex underlies decisions even when viewing duration is dictated by the environment. J. Neurosci. 28, 3017-3029.

Kiefer, M., Adams, S. C., and Zovko, M. (2012). Attentional sensitization of unconscious visual processing: topdown influences on masked priming. Adv. Cogn. Psychol. 8, 50-61.

Kiefer, M., and Brendel, D. (2006). Attentional modulation of unconscious "automatic" processes: evidence from event-related potentials in a masked priming paradigm. J. Cogn. Neurosci. 18, 184-198.

Kiefer, M., and Martens, U. (2010). Attentional sensitization of unconscious cognition: task sets modulate subsequent masked semantic priming. J. Exp. Psychol. Gen. 139, 464-489.

Kiefer, M., and Spitzer, M. (2000). Time course of conscious and unconscious semantic brain activation. Neuroreport 11, 2401-2407.

Kiesel, A., Kunde, W., Pohl, C., Berner, M. P., and Hoffmann, J. (2009). Playing chess unconsciously. J. Exp. Psychol. Learn. Mem. Cogn. 35, 292-298.

King, J. A., Korb, F. M., von Cramon, D. Y., and Ullsperger, M. (2010). Post-error behavioral adjustments are facilitated by activation and suppression of task-relevant and taskirrelevant information processing. J. Neurosci. 30, 12759-12769.

Kinoshita, S., Forster, K. I., and Mozer, M. C. (2008). Unconscious cognition isn't that smart: modulation of masked repetition priming effect in the word naming task. Cognition 107, 623-649.

Kinoshita, S., Mozer, M. C., and Forster, K. I. (2011). Dynamic adaptation to history of trial difficulty explains the effect of congruency proportion on masked priming. J. Exp. Psychol. Gen. 140, 622-636.

Klapp, S. T. (2007). Nonconscious control mimics a purposeful strategy: strength of Stroop-like interference is automatically modulated by proportion of compatible trials. J. Exp. Psychol. Hum. Percept. Perform. 33, 1366-1376.

Klein, T. A., Endrass, T., Kathmann, N., Neumann, J., von Cramon, D. Y., and Ullsperger, M. (2007). Neural correlates of error awareness. Neuroimage 34, 1774-1781.

Kouider, S., Eger, E., Dolan, R., and Henson, R. N. (2009). Activity in face-responsive brain regions is modulated by invisible, attended faces: evidence from masked priming. Cereb. Cortex 19, 13-23.

Kunde, W. (2003). Sequential modulations of stimulus-response correspondence effects depend on awareness of response conflict. Psychon. Bull. Rev. 10, 198-205.

Kunde, W., Kiesel, A., and Hoffmann, J. (2003). Conscious control over the content of unconscious cognition. Cognition 88, 223-242.

Kunde, W., Reuss, H., and Kiesel, A. (2012). Consciousness and cognitive control. Adv. Cogn. Psychol. 8, 9-18.

Lamme, V. A. F. (2006). Towards a true neural stance on consciousness. Trends Cogn. Sci. 10, 494-501.

Lau, H., and Rosenthal, D. (2011). Empirical support for higher-order theories of conscious awareness. Trends Cogn. Sci. 15, 365-373.
Lau, H. C. (2008). A higher order Bayesian decision theory of consciousness. Prog. Brain Res. 168 35-48.

Lau, H. C., and Passingham, R. E. (2007). Unconscious activation of the cognitive control system in the human prefrontal cortex J. Neurosci. 27, 5805-5811.

Li, W., Moallem, I., Paller, K. A., and Gottfried, J. A. (2007). Subliminal smells can guide social preferences. Psychol. Sci. 18, 1044-1049.

Lin, J. Y., Murray, S. O., and Boynton, G. M. (2009). Capture of attention to threatening stmuli without perceptual awareness. Curr. Biol. 19, 1118-1122.

Lleras, A., and Enns, J. T. (2004). Negative compatibility or object updating? A cautionary tale of mask-dependent priming. J. Exp. Psychol. Gen. 133, 475-493.

Marcel, A. J. (1983). Conscious and unconscious perception: experiments on visual masking and word recognition. Cogn. Psychol. 15, 197-237.

Martens, U., Ansorge, U., and Kiefer, M. (2011). Controlling the unconscious: attentional task sets modulate subliminal semantic and visuomotor processes differentially. Psychol. Sci. 22, 282-291.

Martens, U., and Kiefer, M. (2009). Specifying attentional top-down influences on subsequent unconscious semantic processing. Adv. Cogn. Psychol. 5, 56-68.

Marti, S., Sackur, J., Sigman, M., and Dehaene, S. (2011). Mapping introspection's blind spot: reconstruction of dual-task phenomenology using quantified introspection. Cognition 115, 303-313.

Marzouki, Y., Midgley, K. J., Holcomb, P. J., and Grainger, J. (2008). An ERP investigation of the modulation of subliminal priming by exogenous cues. Brain Res. 1231, 86-92.

Mattler, U. (2003). Priming of mental operations by masked stimuli. Percept. Psychophys. 65, 167-187.

Mattler, U. (2005). Inhibition and decay of motor and nonmotor priming. Percept. Psychophys. 67, 285-300.

Mayr, U. (2004). Conflict, consciousness, and control. Trends Cogn. Sci. 8, 145-148.

Mayr, U., Awh, E., and Laurey, P. (2003). Conflict adaptation effects in the absence of executive control. Nat. Neurosci. 6, 450-452.

Merikle, P. M., and Joordens, S. (1997). Parallels between perception without attention and perception without awareness. Conscious. Cogn. 6, 219-236.
Merikle, P. M., and Reingold, E. M. (1990). Recognition and lexical decision without detection: unconscious perception? J. Exp. Psychol. Hum. Percept. Perform. 16, 574-583.

Mudrik, L., Breska, A., Lamy, D., and Deouell, L.Y. (2011). Integration without awareness: expanding the limits of unconscious processing. Psychol. Sci. 22, 764-770.

Mulckhuyse, M., and Theeuwes, J. (2010). Unconscious attentional orienting to exogenous cues: review of the literature. Acta Psychol. 134, 299-309.

Naccache, L., Blandin, E., and Dehaene, S. (2002). Unconscious masked priming depends on temporal attention. Psychol. Sci. 13, 416-424.

Nakamura, K., Dehaene, S., Jobert, A., Le Bihan, D., and Kouider, S. (2007). Task-specific change of unconscious neural priming in the cerebral language network. Proc. Natl. Acad. Sci. U.S.A. 104, 19643-19648.

Nieuwenhuis, S., Ridderinkhof, K. R., Blom, J., Band, G. P. H., and Kok, A (2001). Error-related brain potentials are differentially related to awareness of response errors: evidence from an antisaccade task. Psychophysiology 38, 752-760.

Notebaert, W., Houtman, F., van Opstal, F., Gevers, W., Fias, W., and Verguts, T. (2009). Post-error slowing: an orienting account. Cognition 111, 275-279.

O'Connell, R. G., Dockree, P. M., Bellgrove, M. A., Kelly, S. P., Hester, R., Garavan, H., Robertson, I. H., and Foxe, J. J. (2007). The role of cingulate cortex in the detection of errors with and without awareness: a high-density electrical mapping study. Eur. J. Neurosci. 25, 2571-2579.

O'Connor, P. A., and Neill, W. T. (2011). Does subliminal priming of free response choices depend on task set or automatic response activation? Conscious. Cogn. 20, 280-287.

Ortells, J. J., Fox, E., Noguera, C., and Abad, M. J. (2003). Repetition priming effects from attended vs. ignored single words in a semantic categorization task. Acta Psychol. (Amst.) 114, 185-210.

Ortells, J. J., Frings, C., and PlazaAyllon, V. (2011). Influence of spatial attention on conscious and unconscious word priming. Conscious. Cogn. 21, 117-138.

Overbeek, T. J. M., Nieuwenhuis, S., and Ridderinkhof, K. R. (2005). Dissociable components of error processing: on the functional significance of the Pe Vis-a-vis the ERN/Ne. J. Psychophysiol. 19, 319-329. 
Overgaard, M., Rote, J., Mouridsen, K., and Ramsoy, T. Z. (2006). Is conscious perception gradual or dichotomous? A comparison of report methodologies during a visual task. Conscious. Cogn. 15, 700-708.

Pavone, E. F., Marzi, C. A., and Girelli, M. (2009). Does subliminal visual perception have an errormonitoring system? Eur. J. Neurosci. 30, 1424-1431.

Pessiglione, M., Petrovic, P., Daunizeau, J., Palminteri, S., Dolan, J. D., and Frith, C. D. (2008). Subliminal instrumental conditioning demonstrated in the human brain. Neuron 59, 561-567.

Pessiglione, M., Schmidt, L., Draganski, B., Kalisch, R., Lau, H., Dolan, R. J., and Frith, C. D. (2007). How the brain translates money into force: a neuroimaging study of subliminal motivation. Science 316, 904-906.

Pessoa, L., Kastner, S., and Ungerleider, L. G. (2003) Neuroimaging studeis of attention: from modulations of sensory processing to top-down control. J. Neurosci. 23, 3990-3998.

Pessoa, L., McKenna, M., Gutierrez, E., and Ungerleider, L. G. (2002). Neural processing of emotional faces requires attention. Proc. Natl. Acad. Sci. U.S.A. 99, 11458-11463.

Rahnev, D. A., Huang, E., and Lau, H. (2012). Subliminal stimuli in the near absence of attention influence top-down cognitive control. Atten. Percept. Psychophys. 74, 521-532.

Rajimerhr, R. (2004). Unconscious orientation processing. Neuron 41, 663-673.

Rees, G. (2007). Neural correlates of the contents of visual awareness in humans. Philos. Trans. R. Soc. Lond. B Biol. Sci. 362, 877-886.

Reuss, H., Kiesel, A., Kunde, W., and Hommel, B. (2011). Unconscious activation of task sets. Conscious. Cogn. 20, 556-567.

Ric, F., and Muller, D. (in press). Unconscious addition: when we unconsciously initiate and follow arithmetic rules. J. Exp. Psychol. Gen.

Ridderinkhof, K. R., Ullsperger, M., Crone, E. A., and Nieuwenhuis, S. (2004). The role of the medial frontal cortex in cognitive control. Science 306, 443-447.

Sackur, J., and Dehaene, S. (2009). The cognitive architecture for chaining of two mental operations. Cognition 111, 187-211

Sadaghiani, S., Hesselmann, G., and Kleinschmidt, A. (2009). Distributed and antagonistic contributions of ongoing activity fluctuations to auditory stimulus detection. J. Neurosci. 29, 13410-13417.

Sato, W., Okada, T., and Toichi, M. (2007). Attentional shif by gaze is triggered without awareness. Exp. Brain Res. 183, 87-94.

Schlaghecken, F., and Eimer, M. (2006). Active masks and active inhibition: a comment on Lleras and Enns (2004) and on Verleger, Jaskowski, Aydemir, van der Lubbe, and Groen (2004). J. Exp. Psychol. Gen. 135, 484-494.

Schlaghecken, F., and Martini, P. (2012). Context, not conflict, drives cognitive control. J. Exp. Psychol. Hum. Percept. Perform. 38, 272-278.

Schmidt, F., Haberkamp, A., and Schmidt, T. (2010). Dos and don'ts in response priming research. $A d v$. Cogn. Psychol. 7, 120-131.

Schwarzkopf, D. S., and Rees, G. (2010). Interpreting local visual features as a global shape requires awareness. Proc. R. Soc. Biol. 278, 2207-2215.

Seth, A. K., Dienes, Z., Cleeremans, A., Overgaard, M., and Pessoa, L. (2008). Measuring consciousness: relating behavioural and neurophysiological approaches. Trends Cogn. Sci. 12, 314-321.

Simmonds, D. J., Pekar, J. J., and Mostofsky, S. H. (2008). Metaanalysis of Go/No-go tasks demonstrating that fMRI activation associated with response inhibition is task-dependent. Neuropsychologia 46, 224-232.

Soto, D., Mantyla, T., and Silvanto, J. (2011). Working memory without consciousness. Curr. Biol. 21, R912-R913.

Sterzer, P., Haynes, J. D., and Rees, G. (2008). Fine-scale activity patterns in high-level visual areas encode the category of invisible objects. J. Vis. 8, 10.1-10.12.

Sumner, P., Nachev, P., Morris, P., Peters, A. M., Jackson, S. R., Kennard, C., and Husain, M. (2007). Human medial frontal cortex mediates unconscious inhibition of voluntary action. Neuron 54, 697-711.

Sumner, P., Tsai, P., Yu, K., and Nachev, P. (2006). Attentional modulation of sensorimotor processes in the absence of perceptual awareness. Proc. Natl. Acad. Sci. U.S.A. 103, 10520-10525.

Sweeny, T. D., Grabowecky, M., Suzuki, S., and Paller, K. A. (2009). Longlasting effects of subliminal affective priming from facial expressions. Conscious. Cogn. 18, 929-938.

Tapia, E., Breitmeyer, B. G., and Shooner, C. R. (2010). Role of taskdirected attention in nonconscious and conscious response priming by form and color. J. Exp. Psychol. Hum. Percept. Perform. 36, 74-87.

Tononi, G., and Edelman, G. M. (1998). Consciousness and complexity. Science 282, 1846-1851.

Ullsperger, M., Harsay, H. A., Wessel, J. R., and Ridderinkhof, K. R. (2010). Conscious perception of errors and its relation to the anterior insula. Brain Struct. Funct. 214, 629-643.

Umilta, C. (1988). "The control operations of consciousness," in Consciousness in Contemporary Science, eds A. J. Marcel, and E. Bisiach (Oxford: Oxford University Press), 334-356.

Ursu, S., Clark, K. A., Aizenstein, H. J., Stenger, V. A., and Carter, C. S. (2009). Conflict-related activity in the caudal anterior cingulate cortex in the absence of awareness. Biol. Psychol. 80, 279-286.

van den Bussche, E., Segers, G., and Reynvoet, B. (2008). Conscious and unconscious proportion effects in masked priming. Conscious. Cogn. 17, 1345-1358.

van den Bussche, E., van den Noortgate, W., and Reynvoet, B. (2009). Mechanisms of masked priming: a meta-analysis. Psychol. Bull. 135, 452-477.

van Gaal, S., Lamme, V. A., and Ridderinkhof, K. R. (2010a). Unconsciously triggered conflict adaptation. PloS One 5:e11508. doi: 10.1371/journal.pone.0011508

van Gaal, S., Ridderinkhof, K. R., Scholte, H. S., and Lamme, V. A. F. (2010b). Unconscious activation of the prefrontal no-go network. J. Neurosci. 30, 4143-4150.

van Gaal, S., Ridderinkhof, K. R., Fahrenfort, J. J., Scholte, H. S., and Lamme, V. A. F. (2008). Frontal cortex mediates unconsciously triggered inhibitory control. J. Neurosci. 28, 8053-8062.

van Gaal, S., Ridderinkhof, K. R. van den Wildenberg, W. P. M., and Lamme, V. A. F. (2009). Dissociating consciousness from inhibitory control: evidence for unconsciously triggered inhibitory control in the stop-signal paradigm. J. Exp. Psychol. Hum. Percept. Perform. 35, 1129-1139.

van Gaal, S., Scholte, H. S., Lamme, V. A. F., Fahrenfort, J. J., and Ridderinkhof, K. R. (2011). PreSMA gray-matter density predicts individual differences in action selection in the face of conscious and unconscious response conflict. J. Cogn. Neurosci. 23, 382-390.

van Gaal, S., and Lamme, V. A. F. (in press). Unconscious high-level information processing: implications for neurobiological theories of consciousness. Neuroscientist.

van Opstal, F., Calderon, C. B., Gevers, W., and Verguts, T. (2011a). Setting the stage subliminally: unconscious context effects. Conscious. Cogn. 20, 1860-1864.

van Opstal, F., de Lange, F. P., and Dehaene, S. (2011b). Rapid parallel semantic processing of numbers without awareness. Cognition 120, 136-147.

van Opstal, F., Gevers, W., Osman, M., and Verguts, T. (2010). Unconscious task application. Conscious. Cogn. 19, 999-1006.

Vorberg, D., Mattler, U., Heinecke, A., Schmidt, T., and Schwarzbach, J. (2003). Different time courses for visual perception and action priming. Proc. Natl. Acad. Sci. U.S.A. 100, 6275-6280.

Voss, J. L., Baym, C. L., and Paller, K. A. (2008). Accurate forced-choice recognition without awareness of memory retrieval. Learn. Mem. 15, 454-459.

Voss, J. L., and Paller, K. A. (2009). An electrophysiological signature of unconscious recognition memory. Nat. Neurosci. 12, 349-355.

Voss, J. L., and Paller, K. A. (2010). What makes recognition without awareness appear to be elusive? Strategic factors that influence the accuracy of guesses. Learn. Mem. 17, 460-468.

Vuilleumier, P., and Schwartz, S. (2001). Beware and be aware: capture of spatial attention by fear-related stimuli in neglect. Neuroreport 12, 1119-1122.

Wenke, D., Fleming, S. M., and Haggard, P. (2010). Subliminal priming of actions influences sense of control over effects of action. Cognition 115, 26-38.

Wentura, D., and Frings, C. (2005). Repeated masked category primes interfere with related exemplars: new evidence for negative semantic priming. J. Exp. Psychol. Learn. Mem. Cogn. 31, 108-120.

Whalen, P. J., Kagan, J., Cook, R. G., Davis, F. C., Kim, H., Polis, S., McLaren, D. G., Somerville, L. H., McLean, A. A., Maxwell, J. S., and Johnstone, T. (2004). Human amygdala responsivity to masked fearful eye whites. Science 306, 2061-2061.

Whalen, P. J., Rauch, S. L., Etcoff, N. L., McInerney, S. C., Lee, M. B., and Jenike, M. A. (1998). Masked presentations of emotional facial expressions modulate amygdala activity without explicit knowledge. J. Neurosci. 18, 411-418. 
Wokke, M. E., van Gaal, S., Scholte, H. S., Ridderinkhof, K. R., and Lamme, V. A. (2011). The flexible nature of unconscious cognition. PLoS One 6:e25729. doi: 10.1371/journal.pone.0025729

Wolbers, T., Schoell, E. D., Verleger, R., Kraft, S., McNamara, A., Jaskowski, P., and Buchel, C. (2006). Changes in connectivity profiles as a mechanism for strategic control over interfering subliminal information. Cereb. Cortex 16, 857-864.

Woodman, G. F. (2010). Masked targets trigger event-related potentials index shifts of attention but not error detection. Psychophysiology 47, 410-414.

Zhou, F. A., and Davis, G. (2012). Unconscious priming of task sets: the role of spatial attention. Atten. Percept. Psychophys. 74, 105-114.
Conflict of Interest Statement: The authors declare that the research was conducted in the absence of any commercial or financial relationships that could be construed as a potential conflict of interest.

Received: 29 February 2012; accepted: 17 April 2012; published online: 07 May 2012.

Citation: van Gaal S, de Lange FP and Cohen MX (2012) The role of consciousness in cognitive control and decision making. Front. Hum. Neurosci. 6:121. doi: 10.3389/fnhum.2012.00121 Copyright (c) 2012 van Gaal, de Lange and Cohen. This is an open-access article distributed under the terms of the Creative Commons Attribution Non Commercial License, which permits non-commercial use, distribution, and reproduction in other forums, provided the original authors and source are credited. 